\title{
An audit tool for relicensing inspection for private hospitals in eThekwini district, South Africa
}

\author{
Jamila Chellan ${ }^{1}$, Maureen Nokuthula Sibiya ${ }^{2}$
}

1. Joint Medical Holdings, PO Box 48143, Durban, 4000, South Africa.

2. Faculty of Health Sciences, Durban University of Technology, PO Box 1334, Durban, 4000, South Africa.

\begin{abstract}
:
Background: South Africa is moving towards National Health Insurance (NHI), which aims to provide access to universal health coverage for all South Africans. The NHI will only accredit and contract eligible health facilities that meet nationally approved quality standards in the public and private sector. Detailed tools for measuring compliance with the National Core Standards (NCS) and Batho Pele principles have been developed and implemented in the public sector. To date and since its implementation in the public sector, very little is known about the national audit tool and the method used to evaluate quality and patient safety standards in private hospitals in e'Thekwini district.

Objective: The aim of the study was to develop an audit tool for relicensing inspection of private hospitals in eThekwini district based on the clinical domains of the NCS and Batho Pele principles.

Methodology: An exploratory sequential mixed method research design was used with a qualitative first phase involving 24 nurse managers through purposive sampling. This was followed by a quantitative phase in which a structured questionnaire was administered to 270 nurses who were randomly sampled for the study from 4 hospitals.

Results: The results revealed that the NCS and the Batho Pele principles are not fully implemented or evaluated in the selected hospitals in eThekwini district.

Conclusion: These findings were significant and denoted the need for a standardised clinical audit tool for private hospitals in eThekwini district.

Keywords: Audit tool, best practices, patient care, patient rights, support services.

DOI: https://doi.org/10.4314/ahs.v20i2.49

Cite as: Chellan J, Sibiya MN. An audit tool for relicensing inspection for private hospitals in eThekwini district, South Africa. Afri Health Sci. 2020; 20(2): 936-947. bttps:// doi.org/10.4314/abs.v20i2.49
\end{abstract}

\section{Introduction}

Quality and patient safety in healthcare is of worldwide concern. In recent years, the South African Department of Health has shown an unwavering commitment to improving the quality of health care in the country. This commitment has been put into the spotlight through publication of the 10-Point $\operatorname{Plan}^{1}$ for improvement of the health sector in July 2010. With the onset of the quality movement in the health care sector, a growing interest in the evaluation of the quality of health services has been noted. Licensure, accreditation, and certification are systems available to meet the need for quality

\section{Corresponding author:}

Jamila Chellan, Joint Medical Holdings,

P.O. Box 48143, Durban, 4000, South Africa.

Tel.: +27744755773

Fax. +27862314333

E-mail: jchellan@hotmail.com and performance evaluation of hospitals. However, the nature of health facility licensing is beginning to change in several countries. A traditional physical input approach based on inspections by the Ministry of Health remains the norm in Brazil and Thailand. This traditional model, while still the norm in Canada, is beginning to change with specialty agencies being contracted to carry out inspections. In New Zealand, the emphasis is on abolishing traditional licensing altogether and introducing a certification system with an emphasis on the accumulation of evidence by providers to prove they meet requirements ${ }^{13}$.

According the Minister of Health in South Africa, the importance of providing quality health services is non-negotiable ${ }^{2}$. Better quality of care is fundamental in improving South Africa's current poor health outcomes and in restoring patient and staff confidence in public and private healthcare ${ }^{2}$. The World Health Organisation recommends audit and feedback as a summary of clinical performance of health care over a specified period 
aimed at providing information to health professionals to allow them assess and adjust their performance ${ }^{3}$. All health professionals and institutions have obligations to provide safe and quality health care and to avoid unintentional harm to patients. The scale of patient safety challenges in Africa cannot be underestimated. The All Party Parliamentary Group (APPG) on global health, in its Triple Impact of Nursing report in 2016, argued that "strengthening nursing will have a triple impact on improving quality healthcare, promoting gender equality and supporting economic growth in meeting the needs of its citizens in ensuring accessibility to universal health coverage." Nurses around the world have concerns about staffing problems, poor facilities, inadequate education, training and support ${ }^{16}$.

South African has a dual healthcare system. A public sector run by the national government and a private sector run by hospital groups or by a group of doctors. The majority of private hospitals in South Africa can be classified as short-stay hospitals where most patients are admitted for less than 30 days. The average size of a private hospital is small with less than 200 beds. Private beds constitute 21 percent of total hospital beds in South Africa4. Therefore, private hospitals play a significant role in the South African health care system. The changing preferences of the medical scheme population have influenced a significant shift from utilisation of public hospitals to private hospitals 4 since 1990. Nurses in the private sector are expected to show a high level of empathy and assurance in the quality dimension that will impact a customer's loyalty and cumulative satisfaction of the service ${ }^{5}$. However, there has not been a standardised system or legislative requirement for private hospitals to submit information on clinical outcomes ${ }^{4}$. Implementation of quality and patient safety initiatives have thus been left to the discretion of each hospital. The Office of Health Standards Compliance is the custodian of the national quality standards which are based on existing policy environment and tailored to South Africa's healthcare context, while also reflecting international best practice ${ }^{6}$. The White Paper on Batho Pele transformational principles sought to address two issues: putting people first, and viewing the recipients of services as customers. It is a policy framework that consists of eight service delivery principles that are deemed to represent an appropriate approach to address service delivery challenges ${ }^{7}$. The purpose of the NCS and its six fast tracked standards which embodies the Batho Pele principles provides a common definition of quality care which should be found in all health establishments in South Africa as preparations are underway to implement the NHI2. It is therefore imperative for private sector hospitals to be included in the preparations for NHI which further emphasises the need for a common audit tool for national level audits for both the private and public sector hospitals. While the structural audit tool using R158 is known to the private sector, no such tool exists for the measurement of clinical practice standards within private hospitals in eThekwini district ${ }^{8}$. Clearly, then a need exists for an objective way of measuring clinical performance of private hospitals using an appropriate audit tool. There is a close relationship between hospital performance measurement and quality improvement which emanates from the basic premise that when you start measuring the clinical performance of a hospital you will discover areas of concern and in addressing these concerns the overall quality of the healthcare service will improve. This connection between the overall organization performance and quality means that any tools used to improve the quality of hospital healthcare services will give a measure of how well the hospital is performing. An interesting finding is that performance measurements in hospitals and quality improvement are so interrelated that it is impossible to measure one without the other ${ }^{10}$.

The literature reviewed suggested that there are gaps between public and private sector regulatory relicensing inspections in eThekwini district ${ }^{9-10}$. However it is difficult to explain the exact measures of quality and patient safety variations within private hospitals without a standardised audit tool for evaluation. In order to develop a clinical audit tool for relicensing inspections, the researcher had to first identify the levels of variations of quality and patient safety standards in the private group of hospitals in relation to the NCS and the Batho Pele principles (Figure 1). 


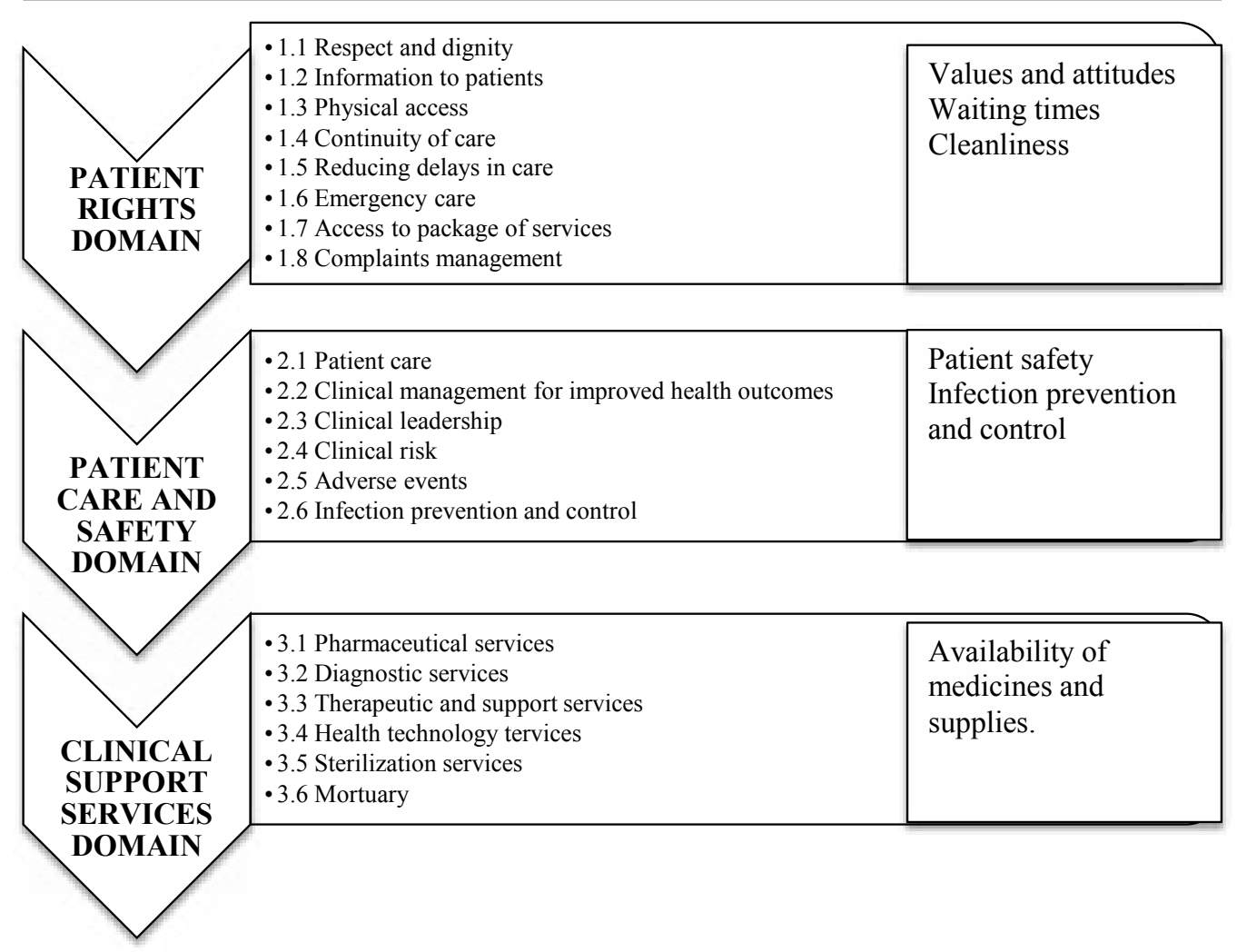

Figure 1: Structure of the NCS Clinical Domains and Sub-Domains reflecting the six critical areas Source ${ }^{2}$

\section{Methodology \\ Setting}

The research setting was a group of four private hospitals situated in the eThekwini district. The group comprises 650 beds with an average bed occupancy of $80 \%$. The private hospitals chosen are all part of a larger hospital group which are regulated by the eThekwini Department of Health and seek relicensing on an annual basis.

\section{Study design}

The researcher employed an exploratory sequential mixed methods research design (QUAL $\rightarrow$ QUAN) to assess elements from both the qualitative and quantitative paradigms. In this exploratory sequential mixed method research design, the researcher sought to elaborate and expand the findings of one method with another method. This involved beginning with a qualitative method for exploratory purposes which was fol- lowed by a quantitative method, a survey with a larger sample population followed by documentation review so that with a larger sample the researcher could generalize results to a population 11 .

\section{Sampling and sampling technique}

The selected group of hospitals has 40 clinical managers who were included in the qualitative phase of the study as they are directly involved in relicensing inspections. The participants $(n=24)$ were interviewed face-to-face guided by data saturation. The quantitative phase included nursing staff in direct contact with the patients. The total population of nurses was 569 of whom 270 were sampled for the study, from each of the hospitals in the study. Exclusion criteria included agency staff, nurses that were not registered with the South African Nursing Council, non-clinical staff and those that were used for the pre-testing of data collection instruments. 


\section{Data collection}

The researcher during her weekly visits to the research sites invited the participants to take part after briefing them using the information letter. Data collection took place between September and December 2016. All participants who agreed to take part in the study signed an informed consent form. The informed consent included an explanation of the consent form, confidentiality issues and anonymity procedures for participants, and the option to withdraw at any time.

\section{Qualitative data collection: Phase 1}

Data collection explored the views of the senior nursing managers who are instrumental in supervising quality and patient safety standards, using an interview guide supplemented with probing questions. The qualitative design was chosen in order allow the nurse managers to express their views in their own words and share their experiences of the current relicensing inspections as they are directly involved in regulatory relicensing process. The interview focused on the standards of the first three clinical domains of the NCS and Batho Pele principles, that is, the Patient rights, Patient care and Support services domains. The time taken to complete the interviews was aimed at 30 minutes. The interviews were recorded and transcribed verbatim by the researcher with the permission of the participants. Probing questions were used to further clarify and to uncover answers, where participants were required to explain or build on their responses related to the clinical domains of the NCS and the Batho Pele principles. Data collection continued until the point of data saturation. All the interviews were conducted by the researcher during her visits to the four research sites.

\section{Quantitative data collection: Phase 2}

The qualitative phase identified specific variables which were then used to build an instrument for the follow-up quantitative phase of the study. The intent of this strategy was to develop better measurements with specific samples of populations and to see if data from a few individuals gathered in a qualitative phase can be generalised to a large sample of a population in a quantitative phase $^{11}$. The nursing staff were the participants in the quantitative phase of the study as they are the clinicians at the bedside. The quantitative design was chosen as an appropriate method for assessing the perceptions of the nursing staff with regards to their relicensing experience as they are the staff who performs the clinical duties. The questionnaires on average took about 20 minutes to complete.

\section{Documentation review: Phase 3}

Secondary data was obtained from documents such as the organisational specific policies and procedures. It represented the data to which participants had given attention during the qualitative and quantitative phases of the study ${ }^{11}$. The documentation review further enabled the researcher to link the concepts raised in the first two phases to the conceptual framework under study. The NCS and Batho Pele principles are two of the documents on which the documentation review was based and offered guidance on the policies and procedures required to provide quality and safe patient care. A checklist was developed based on the standards and protocols of quality and patient safety, identified by the participants in the first two phases of the study.

\section{Research Rigor}

Procedural rigour was ensured through documentation of all the steps and processes taken to conduct the study and how the decisions were reached until the establishment of an audit trail. Interpretive rigour was ensured by basing the data analysis on the three clinical domains of the National Core Standard and the Batho Pele principles as the conceptual framework that was used to guide the study and constantly adhering to the strategies that were inherent within the qualitative design during the data interpretation stage. The researcher used a voice recorder to ensure that data were accurately recorded and representative of the data as a whole. Verbatim translation of data included non-verbal cues displayed by the study's participants during the interviews. The techniques to ensure trustworthiness followed Lincoln and Guba recommendations17 using the criteria namely: credibility, dependability, confirmability, and generalizability.

The research rigour in the quantitative phase of the study was emphasized through the concepts of reliability and validity of the methods used for data collection and data analysis. The researcher piloted the structured questionnaire with five percent of the total sample population to test the validity of the tool. The pilot study further ensured content and construct validity demonstrating that the questions were clearly understood by the participants. Any ambiguities or inaccuracies pertaining to the questions were corrected before administering the tool to the participants in the main research study. The time taken to complete the questionnaires which was aimed at 30 minutes was determined. The data analysed in the pilot study was not included in the main study. The researcher collected high-quality data 
using a good psychometric instrument, measuring variables that are accurate and valid. The researcher had consulted with fellow nursing managers of other private groups and nursing experts in the field of quality management.

\section{Data analysis}

The study consisted of two data sets: quantitative data and qualitative data both of which needed to be analysed and interpreted to conclude study findings and to develop a clinical relicensing audit tool during the final stage of the study. The data sets were first analysed independently using analytic approaches suited for each strand. The results of the data sets were then compared. The first three clinical domains of the NCS and Batho Pele principles were used to guide the analysis and the comparisons of the qualitative and quantitative results.

\section{Qualitative data analysis}

The approach adopted for qualitative data analysis was an inductive approach. The researcher focused on describing how many times different concepts appeared in the data and linked them to codes to create meaning. Important quotations from the participants' responses were identified. The concepts were translated into codes, codes into themes and categories. The themes according to which data was organised were predetermined according to the conceptual framework that guided the study.

\section{Quantitative data analysis}

Data from the quantitative data set were analysed in two forms. The first analysis included a composite analysis of the entire data set to assess how the four hospitals performed in relation to the objective of the study, broadly understood by participants as assessment by the auditors. Secondly comparisons were made between the four hospitals. The researcher used SPSS version 24.0 for data analysis. The following tests were used in the analysis of the quantitative data: Descriptive statistics including means and standard deviations, where applicable frequencies were represented in tables or graphs; the Chi-square goodness-of-fit-test; A univariate test was used on a categorical variable to test whether any of the response options were selected significantly more/ less often than that of the others.

The merging and integration of data sets was achieved through triangulation of the different data sources and combining the results together to compare, validate and collaborate the results ${ }^{11}$. Through the merging and integration of the different data sources the researcher was further able to collaborate and validate the findings of the qualitative results in relation to its main and subthemes through analyzing the significant agreements and disagreements from the participants in the quantitative phase of the study.

The conceptual framework of the NCS and Batho Pele principles guided the development of the proposed audit tool whereby the researcher first identified the key concepts to be used within the audit tool (Figure 2). The researcher identified how the various processes within the clinical domains was assessed during relicensing inspections and how the current best practices at the organizations provided quality and patient safety in terms of the requirements of the NCS and the Batho Pele principles. The researcher also analyzed documents in the form of policy and procedures that exists within the organizations and how relevant they were in meeting the objectives of the NCS and the Batho Pele principles. 


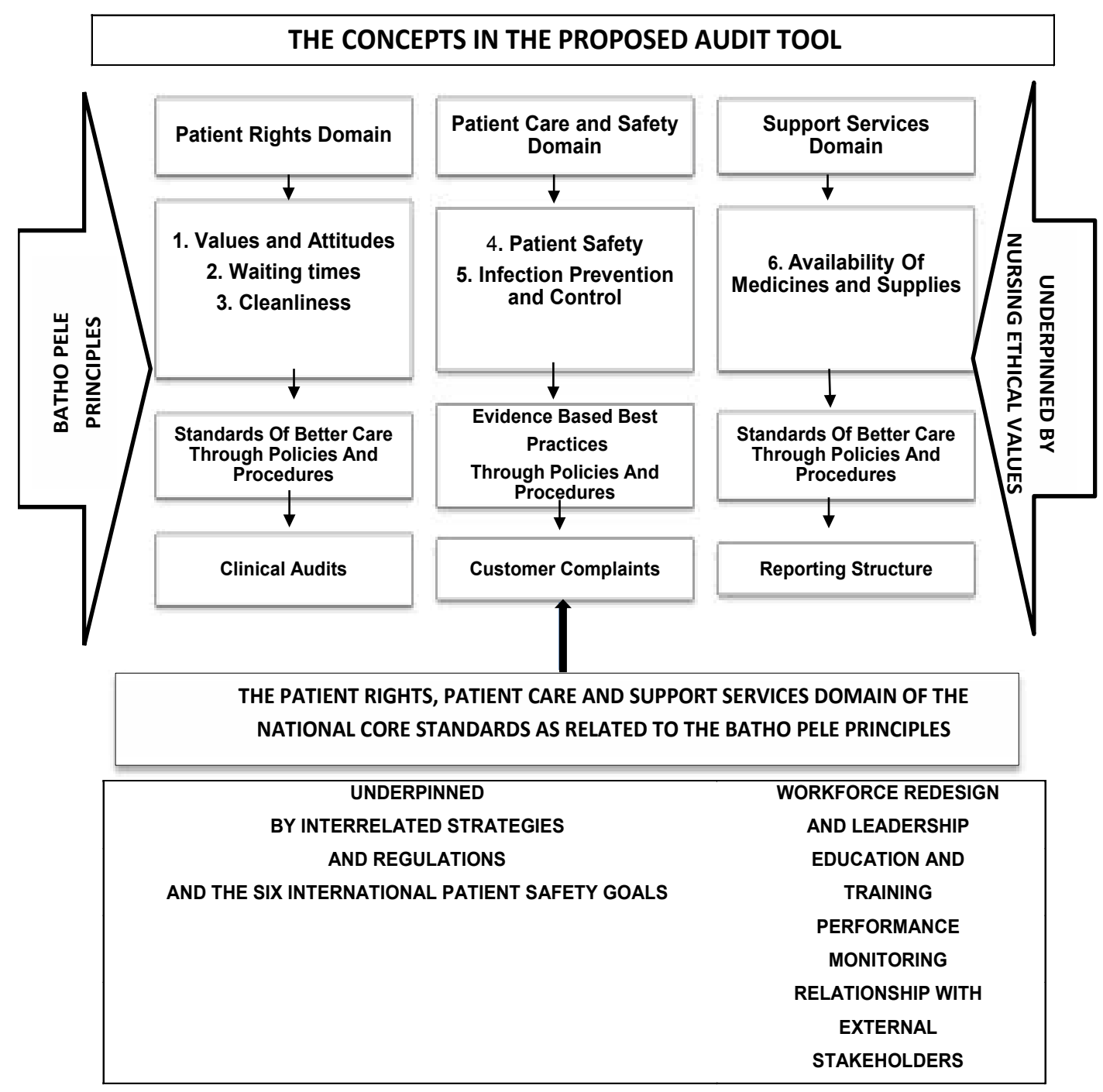

Figure 2: The concepts in the proposed audit tool. Adapted from Source ${ }^{2}$

\section{Results}

The overall results of the patients' rights, patient care and support services domains showed that the findings from the quantitative phase validated the findings of the qualitative phase in which the main theme was that there is inadequate checking of these domains by the auditors during relicensing inspection. In addition, in the quantitative phase of the study, the responses from the open-ended question from participants, $61 \%(n=77)$ offered recommendations, for a standardised audit tool for relicensing inspection. The quantitative results also showed that participants agreed that only four of the eight patient's right subdomains are assessed during relicensing inspections.

\section{Phase 1: Qualitative results}

There were three major themes and several sub-themes that emerged during the qualitative data analysis related to the Patients Right, Patient Care and Support Services domains.
Major theme 1: Inadequate checking of the Patient Rights domain during relicensing inspection When participants were asked if the annual relicensing inspection included aspects of the Patient Rights domain during relicensing inspections, most of the participants expressed their unconscious prejudices toward the current relicensing process based on their interpretation of the NCS and Batho Pele principles as well as shared their own personal experiences as a yardstick for relicensing inspection regarding the Patient Rights domain. The three sub-themes that emerged under this major theme during the interview were: Inconsistent checking of the Patient Rights domain during relicensing inspection; Lack of an audit tool for clinical audits during relicensing inspections and Recommendations for a standardised tool for clinical audits. There were mixed responses to this question as participants articulated their own viewpoints as per their perceptions and expressed some of the following sentiments regarding this domain: 
"The audit is based on the R158 ... very little to do with clinical ... and infection control. More focused on bed spacing ... structure ... It is relevant to infection control. I agree it is interrelated, but they do not look at respect and dignity" (Participant 3, Hospital C). "Honestly... inspections are very generic inspections ... they should firstly have an audit tool to give us guidance. There are no checklists as well ... not done completely with regards to ... respect and dignity ... this is not being checked. It would be nice to have a tool ... benchmarking will really work well for each hospital' (Participant 3, Hospital B).

Major theme 2: Inadequate checking of the Patient Care domain during relicensing inspection

Six sub-themes emerged under this major theme during the interview. There were mixed responses to this question. Many participants expressed sentiments regarding their own evidence-based practices. Excerpts from participants included:

"My ward is an infectious unit ... the only thing they checked was the dispensers... They should check the sputum room, policies, smoke tests done ... check our isolation wards for negative pressure, check the hygrometers on the wall ... my infectious policies ... should question about MDR (Multiple Drug Resistance) patients curtain washing plan ... how we soak our dishes ... how we isolate our patients, our PPE's and our staff medicals. There was not a single question regarding infection control' (Participant 5, Hospital A).

"Yes, they look at this at unit level ... they look at negative pressure. Not all isolation rooms are checked ... They should have an audit tool ... based on the tool they should check PTB's (Pulmonary Tuberculosis) ... if screened ... isolated and management of MDR and XDR (Extreme Drug Resistance) patients" (Participant 3, Hospital B).

Major theme 3: Inadequate checking of the Clinical Support Services domain during relicensing inspection One sub-theme emerged under this major theme: there is inconsistent checking of Clinical Support Services during relicensing inspection. Excerpts from participants included:

"Diagnostic Services ... no ... I have not seen this. They don't check and audit blood gas machines and critical equipment checks are not audited" (Participant 3, Hospital A).

"Yes, they did check my ventilators, they checked my last service date on my ventilator. They even checked my certification of services ... my yearly certification of services whether they done and concurrent and then I had to submit a critical care register to annotate the next service date" (Participant 7, Hospital A).

\section{Phase 2: Quantitative results}

The number of participants in the quantitative phase was from four hospitals coded as Hospital A, B, C and D. A total of 270 questionnaires were distributed. The total number of questionnaires that were received and included in the data analysis and interpretation was 234 from all four hospitals with an overall return rate of $86.7 \%$.

\section{Assessment of the Patient Rights Domain by the Auditors}

Participants were asked if the eight sub-domains within the Patient Rights domain were adequately assessed by the auditors during relicensing inspection. The following mean total responses were received for the various standards within the sub-domains across all four hospitals coded as Patient Rights (PR1-8). For respect and dignity, the mean score was $4.20(\mathrm{n}=233)$, information to patients $3.36(n=231)$, physical access $4.33(n=231)$, continuity of care $3.25(\mathrm{n}=233)$, reducing delays in care $3.31(\mathrm{n}=231)$, emergency care $3.31(\mathrm{n}=232)$, access to packages of service $4.16(n=232)$ and complaints management $4.19(\mathrm{n}=232)$.

\section{Assessment of the Patient Care Domain by the Au- ditors}

The results of the study showed that when the participants were asked if aspects of the Patient Care domain were adequately assessed by the auditors during relicensing inspection there were positive and negative reponses elicited. The following total mean responses were received for the various standards within the $\mathrm{Pa}$ tient Care sub-domain across all four hospitals, coded as Patient Care (PC 1-25). For Morse falls risk assessment tool for prevention of patient falls the mean was 3.75 ( $n=234)$, Waterloo risk assessment tool for the prevention of pressure sores $3.76(n=233)$, IV cannulation bundle practice for the prevention of phlebitis 3.71 $(n=234)$, hang-times for antibiotics $3.76(n=234)$, chlorhexidine prewash before surgery $3.55(n=234)$, bundle practice for the prevention of SSI $3.65(n=233)$, bundle practice for the prevention of ventilator acquired pneumonia $3.57(\mathrm{n}=234)$, bundle practice for the prevention of catheter associated UTI $3.60(n=234)$, and bundle practice for the prevention of central line arterial bloodstream infection $3.53(n=234)$. Observation of the 5 Rs of medication administration $3.79(n=234)$, observation of the six international patient safety goals $4.26(n=234)$, change of shift report using situation, background, assessment and recommendation 3.49 $(\mathrm{n}=234)$, adequate care in the handling of sharps 3.79 $(\mathrm{n}=233)$, proper care in the handling of medical waste $3.91(n=234)$, maintenance of standard precautions to 
prevent cross infection $4.41(\mathrm{n}=234)$, consistent application of hand hygiene principles $4.54(n=234)$, daily monitoring of environmental risks $4.37 \quad(\mathrm{n}=234)$, safe administration of blood and blood products 3.45 $(\mathrm{n}=233)$, timeous reporting of adverse events 3.61 $(\mathrm{n}=233)$, following the time-out process for all invasive and surgical procedures $3.48(\mathrm{n}=233)$, adherence to inter-hospital and inter-departmental transfers processes $3.44(n=234)$, understanding your job description 4.65 $(n=234)$, participation in induction and orientation programmes $4.41(\mathrm{n}=233)$, participation in ward in-service training programmes $4.36(\mathrm{n}=234)$, and knowledge of unit policies and procedures $4.56(\mathrm{n}=234)$.

\section{Assessment of the Clinical Support Services Do- main by the Auditors}

Seven questions relating to the clinical support services domains were asked in the survey. The results of the study showed that when the participants were asked if aspects of the clinical support services domain were adequately assessed by the auditors during relicensing inspections there were both positive and negative responses elicited. The following total mean responses were received for the various standards within the clinical support services sub-domain across all four hospitals, coded as Support Services (SS 1-7). For checking of the pharmacy related issues in the unit, the mean score was 3.21 $(n=234)$, checking of diagnostic services in the unit 3.41 ( $\mathrm{n}=233$ ), checking of health technology services in the unit $3.47(n=234)$, checking of sterilisation services in the unit $3.43(\mathrm{n}=233)$, checking of mortuary services in the unit $2.87(\mathrm{n}=225)$, checking of efficiency management services in the unit $4.20(n=234)$, checking of therapeutic and support services in the unit $3.59(n=233)$.

There were also internal and external factors identified with the current clinical audit process (Table 1).

Table 1: Internal and external factors identified by senior managers

\begin{tabular}{|c|c|}
\hline $\begin{array}{l}\text { INTERNAL FACTORS } \\
\text { Factors contributing to the lack of confidence }\end{array}$ & Factors that could improve confidence \\
\hline $\begin{array}{l}\text { Lack of management exposure to relicensing audits based } \\
\text { on NCS and Batho Pele principles. }\end{array}$ & $\begin{array}{l}\text { Internal audit procedures must incorporate aspects of the } \\
\text { three clinical domains. }\end{array}$ \\
\hline Ineffective communication between the teams. & Improve communication through regular quality forums. \\
\hline Lack of timeous feedback regarding audits. & $\begin{array}{l}\text { Improve feedback to the managers and provide } \\
\text { constructive criticisms. }\end{array}$ \\
\hline Inadequate preparations for audits. & $\begin{array}{l}\text { Encourage continuous quality improvement and readiness } \\
\text { for audits at all times. }\end{array}$ \\
\hline Uncertainty of what is going to be checked. & Prepare for audits within the national audit guidelines. \\
\hline $\begin{array}{l}\text { Lack of experience of unit managers to conduct external } \\
\text { audits. }\end{array}$ & $\begin{array}{l}\text { Accompaniment and mentorship incorporated into } \\
\text { leadership programmes. }\end{array}$ \\
\hline \multicolumn{2}{|l|}{ EXTERNAL FACTORS } \\
\hline Factors contributing to the lack of confidence & Factors that could improve confidence \\
\hline Lack of a standardised audit tool with benchmarks. & $\begin{array}{l}\text { Implement the National Audit tool for private sector } \\
\text { relicensing inspections. }\end{array}$ \\
\hline Audit not based on the NCS and the Batho Pele principles. & $\begin{array}{l}\text { The NCS and Batho Pele principles framework of quality } \\
\text { and patient safety to be applied to private sector hospitals. }\end{array}$ \\
\hline Lack of consistency within the audits. & $\begin{array}{l}\text { Provide standardised auditable checklists for clinical } \\
\text { inspections to ensure consistency. }\end{array}$ \\
\hline Lack of timeous and objective feedback. & $\begin{array}{l}\text { Feedback in the form of a score rating identifying the } \\
\text { high-risk areas while on site. }\end{array}$ \\
\hline Combined structural and clinical audits. & Separate the R158 structural audit from the clinical audit. \\
\hline The approach and attitude of audit staff. & Friendly attitude will put staff at ease. \\
\hline Not recognised as an educational opportunity. & $\begin{array}{l}\text { Use the process as an opportunity to educate staff at all } \\
\text { levels. }\end{array}$ \\
\hline
\end{tabular}

\section{Comparisons between the four hospitals}

The construct measures for the assessment by the auditors and the assessment of Best Practices was compared for the four hospitals using the Krusal Wallis Test. The results of the assessment measures differed significantly across the 4 hospitals in the study.

\section{Discussion}

The overall results from the quantitative study corroborated the findings of the qualitative phase. The results of the study clearly indicated that the expectations of the regulator are not being met during relicensing inspections for the selected private hospitals in eThekwini district. The Patient Rights, Patient Care and Sup- 
port Services domains are inadequately checked against the clinical domains of the NCS and the Batho Pele principles during relicensing inspections. These inconsistencies in licensing and relicensing audits can relate to previous studies which have indicated that a lack of effective communication on part of the regulator may lead to major target areas being unchecked, especiallyin high-risk areas of the organisation ${ }^{12-13}$. Respect is central to a culture of compassionate care in nursing practice, in the vision and strategy for nurses and midwives ${ }^{14}$. The results of the study showed inconsistencies in checking these standards during relicensing inspection. Patient Rights is advocated and practised internationally, and the Joint Commission International (JCI) with its six international patient safety goals advocates that the organisation as a whole has to establish a framework for ethical management that ensures that patient care is provided within business, financial, ethical and legal norms that protect patients and their rights ${ }^{15}$. An audit tool for relicensing inspection for private
hospitals in eThekwini district, South Africa

The audit tool developed is a matrix of healthcare clinical performance domains which can be compared against a set of current evidence-based practice standards and criteria measuring clinical outcomes in private hospitals in eThekwini district (Tables 2, 3, 4). The advantage of a standardised audit tool is that it will provide an opportunity to benchmark outcomes of high-risk clinical practices in the private sector both nationally and internationally. The regulator will achieve its objectives of ensuring that at least minimal levels of quality health services are maintained at private hospitals in eThekwini district in a consistent way. The need for continuous quality improvement and successful relicensing on an annual basis is the key to success and survival of private hospitals in a very competitive healthcare environment.

Table 2: Patient Rights domain: The proposed Clinical Audit Tool for relicensing inspection for private hospitals in eThekwini district

\begin{tabular}{|c|c|c|c|c|c|}
\hline $\begin{array}{l}\text { 1. Patient Rights } \\
\text { domain }\end{array}$ & $\begin{array}{l}\text { Patient Rights upheld, including getting a } \\
\text { seen from the point of view of the patient, }\end{array}$ & $\begin{array}{l}\text { cess to needed care and to respectful, informed and dignified attention ir } \\
\mathrm{n} \text { accordance with Batho Pele principles and the Patient Rights Charter }\end{array}$ & an acceptable and hy & gienic environment, & Score \\
\hline Sub-domain & Standard & Criteria & Measure & Outcome & Score \\
\hline $\begin{array}{l}1.1 \text { Respect and } \\
\text { Dignity }\end{array}$ & $\begin{array}{l}\text { Staff treat patients with care and respect, } \\
\text { with consideration for patient privacy and } \\
\text { choice and allow patients to express } \\
\text { dissatisfaction. }\end{array}$ & $\begin{array}{l}\text { Empathy, privacy, care of the vulnerable, patient satisfaction, } \\
\text { environment of care, food and water. Display Batho Pele, Patient Charter, } \\
\text { Patients' rights and responsibilities. Mission,Vision and } \\
\text { Objectives .Assess confidentiality related to POPI act. }\end{array}$ & $\begin{array}{c}\text { Policy } \\
\text { Procedures } \\
\text { Directives } \\
\text { Staff Education }\end{array}$ & $\begin{aligned} E= & 0 \%-20 \% \\
D & =20 \%-39 \% \\
C & =40 \%-59 \% \\
B & =60 \%-79 \%\end{aligned}$ & $\begin{array}{c}\text { A-E } \\
\text { C } \\
\mathrm{N}-\mathrm{C}\end{array}$ \\
\hline $\begin{array}{l}1.2 \text { Information to } \\
\text { Patients }\end{array}$ & $\begin{array}{l}\text { Patients are given the information they } \\
\text { need regarding their treatment, their care } \\
\text { after discharge, and their participation in } \\
\text { research where relevant. }\end{array}$ & $\begin{array}{l}\text { Patients' rights and responsibility explained, informed consent, discharge } \\
\text { summary reports, research approval, information to patient's assessed } \\
\text { adequate signage, visiting hours, and nurses' identification. }\end{array}$ & $\begin{array}{l}\text { Direct Access } \\
\text { Direct Observations } \\
\text { Score Cards }\end{array}$ & $\begin{array}{c}\mathrm{A}=80 \% 100 \% \\
\quad \text { Compliant } \\
\text { Non-compliant }\end{array}$ & \\
\hline $\begin{array}{l}1.3 \text { Physical } \\
\text { Access } \\
1.4 \text { Continuity of } \\
\text { Care }\end{array}$ & $\begin{array}{l}\text { Services are easy and safe to access } \\
\text { including for the disabled. } \\
\text { Patients are given information about } \\
\text { referrals and specialist bookings. }\end{array}$ & $\begin{array}{l}\text { Easy and safe access to hospital, access for disabled, hearing and visually } \\
\text { impaired ambulation of disabled persons. } \\
\text { Referral systems, emergency care, resources are adequate. Staff is BLS } \\
\text { trained. }\end{array}$ & & & \\
\hline $\begin{array}{l}1.5 \text { Reducing } \\
\text { Delays in Care. }\end{array}$ & $\begin{array}{l}\text { Waiting times for bed placements, } \\
\text { outpatients and procedures are managed to } \\
\text { improve patient satisfaction and care, and } \\
\text { triage of patients ascertain their priority } \\
\text { levels of care. }\end{array}$ & $\begin{array}{l}\text { Reduce-waiting times, receive medications timeously, treatment } \\
\text { according nature and severity of condition, efficient filing system, } \\
\text { waiting lists for elective procedures kept short. }\end{array}$ & & & \\
\hline $\begin{array}{l}1.6 \text { Emergency } \\
\text { Care. }\end{array}$ & $\begin{array}{l}\text { Emergency patients are attended to, } \\
\text { examined and stabilised appropriately and } \\
\text { then referred or transferred if needed. }\end{array}$ & $\begin{array}{l}\text { Effective handover, guidelines for stabilising patients at A-E units, } \\
\text { hospital and ambulance diversions to minimise impact. }\end{array}$ & & & \\
\hline $\begin{array}{l}1.7 \text { Access to } \\
\text { Package of } \\
\text { Service. }\end{array}$ & $\begin{array}{l}\text { Services provided meet with national } \\
\text { guidelines or licensing specifications. }\end{array}$ & All services meet the guidelines of R158. & & & \\
\hline $\begin{array}{l}1.8 \text { Complaints } \\
\text { Management. }\end{array}$ & $\begin{array}{l}\text { Patients who wish to complain about poor } \\
\text { service are helped to do so and their } \\
\text { concerns are properly addressed and used } \\
\text { to improve the service. }\end{array}$ & $\begin{array}{l}\text { Complaints management, addressed within timescales, complaints used } \\
\text { to improve quality of service. Complaints are screened to identify and } \\
\text { manage adverse events. }\end{array}$ & & & \\
\hline
\end{tabular}


Table 3: Patient Safety, Clinical Governance and Clinical Care domain: The proposed Clinical Audit Tool for relicensing inspection for private hospitals in eThekwini district

\begin{tabular}{|c|c|c|}
\hline $\begin{array}{l}\text { 2. Patient Safety } \\
\text { Clinical } \\
\text { Governance and } \\
\text { Clinical Care } \\
\text { domain }\end{array}$ & \multicolumn{2}{|c|}{$\begin{array}{l}\text { The Patient Safety, Clinical Governance and Clinical Care domain covers how to ensure quality nursing } \\
\text { harm to healthcare users or patients in identified cases of greater clinical risk; prevent or manage probler } \\
\text { infections; and support any affected patients or staff. }\end{array}$} \\
\hline Sub-domain & Standard & Criteria \\
\hline 2.1 Patient Care. & $\begin{array}{l}\text { Patients receive care and treatment that } \\
\text { follows nursing protocols, EBP and } \\
\text { meets basic needs and contributes to } \\
\text { their recovery. }\end{array}$ & $\begin{array}{l}\text { Processes are in place to ensure basic and EBP care with } \\
\text { continuous quality improvement. }\end{array}$ \\
\hline $\begin{array}{l}2.2 \text { Clinical } \\
\text { Management for } \\
\text { Improved } \\
\text { Outcomes. }\end{array}$ & $\begin{array}{l}\text { Care provided contributes positively to } \\
\text { national priorities, including the United } \\
\text { Nations Millennium Development Goals } \\
\text { for maternal and child health, HIV and } \\
\text { Tuberculosis. }\end{array}$ & $\begin{array}{l}\text { Processes are in place to ensure basic and EBP care with } \\
\text { continuous quality improvement. }\end{array}$ \\
\hline $\begin{array}{l}2.3 \text { Clinical } \\
\text { Leadership. }\end{array}$ & $\begin{array}{l}\text { Doctors, nurses and other health } \\
\text { professionals constantly work to } \\
\text { improve the care they provide through } \\
\text { proper support systems. }\end{array}$ & $\begin{array}{l}\text { Appropriate HOD's, job description with lines of accountability. } \\
\text { Formal supervision programme. Quality Committee in place. }\end{array}$ \\
\hline 2.4 Clinical Risks. & $\begin{array}{l}\text { Clinical risk identification and analysis } \\
\text { takes place in every ward to prevent } \\
\text { patient safety incidents. }\end{array}$ & $\begin{array}{l}\text { Clinical risk identification in every ward, clinical risk policy and } \\
\text { protocol, monitoring systems, for high-risk patients, mentally ill } \\
\text { patients. }\end{array}$ \\
\hline $\begin{array}{l}2.5 \text { Adverse } \\
\text { Events. }\end{array}$ & $\begin{array}{l}\text { Adverse events or patient safety } \\
\text { incidents are promptly identified and } \\
\text { managed to minimise patient harm and } \\
\text { suffering. }\end{array}$ & $\begin{array}{l}\text { Adverse events policy and procedure, incident reporting and } \\
\text { monitoring system, control and corrective actions, adverse events } \\
\text { are monitored against set targets. }\end{array}$ \\
\hline $\begin{array}{l}2.6 \text { Infection } \\
\text { Prevention and } \\
\text { control. }\end{array}$ & $\begin{array}{l}\text { An Infection Prevention and Control } \\
\text { Programme is in place to reduce } \\
\text { healthcare-associated infections. }\end{array}$ & $\begin{array}{l}\text { Infection prevention and control policy to manage HAIs. A } \\
\text { qualified health professional is in charge. A formal surveillance, } \\
\text { monitoring and reporting system is in place to reduce infection } \\
\text { rates. Notifiable diseases process is in place. EBP to prevent HAI. } \\
\text { Isolation Procedures. Sharps handling, environmental monitoring, } \\
\text { respiratory/TB conditions. Preparation of feeds, hand hygiene and } \\
\text { waste management. }\end{array}$ \\
\hline
\end{tabular}

Table 4: Clinical Support Services domain: The proposed Clinical Audit Tool for relicensing inspection for private hospitals in eThekwini district

\begin{tabular}{|c|c|c|c|c|c|}
\hline $\begin{array}{l}\text { 3. The Clinical } \\
\text { Support Services }\end{array}$ & \multicolumn{5}{|c|}{$\begin{array}{l}\text { The Clinical Support Services domain covers specific services essential in the provision of clinical care and includes the timely availability of medicines and efficient provision } \\
\text { of Diagnostic, therapeutic and other clinical support services and necessary medical technology, as well as systems to monitor the efficiency of the care provided to patients. }\end{array}$} \\
\hline Sub-domain & Standard & Criteria & Measure & Outcome & Score \\
\hline $\begin{array}{l}\text { 3.1 Pharmaceutical } \\
\text { services. }\end{array}$ & $\begin{array}{l}\text { Pharmaceutical services are licensed and } \\
\text { are supervised by a registered pharmacist. } \\
\text { Stock levels and storage of medicines and } \\
\text { medical supplies are managed } \\
\text { appropriately. Reactions to drugs or } \\
\text { severe side effects are reported and the } \\
\text { patient is properly cared for. }\end{array}$ & $\begin{array}{l}\text { The pharmacy is licensed by National Department of Health, registered } \\
\text { by SAPC. Medicines are stored in compliance with the Pharmacy Act, } \\
\text { Responsible pharmacist. Medical supplies required to care for patients } \\
\text { are in stock. Access to medicines during operating hours and after } \\
\text { hours. Advice is given to patients to adhere to therapy. Prescribing } \\
\text { complies with applicable guidelines and policies, Schedule } 5 \text { and } 6 \\
\text { medicines are controlled and distributed in accordance with the } \\
\text { Medicines and Related Substances Act. }\end{array}$ & $\begin{array}{l}\text { Policy } \\
\text { Procedures } \\
\text { Directives } \\
\text { Staff Education } \\
\text { Direct Access } \\
\text { Direct Observations } \\
\text { Minutes of meetings } \\
\text { Environmental monitoring }\end{array}$ & $\begin{array}{l}E=0 \%-20 \% \\
D=20 \%-39 \% \\
C=40 \%-59 \% \\
B=60 \%-79 \% \\
A=80 \%-100 \% \\
\text { Compliant } \\
\text { Non-compliant }\end{array}$ & $\begin{array}{l}\text { A- E } \\
\text { C } \\
\text { N-C }\end{array}$ \\
\hline $\begin{array}{l}\text { 3.2 Diagnostic } \\
\text { Services. }\end{array}$ & $\begin{array}{l}\text { X-ray services are available and provide } \\
\text { good quality reports or results within } \\
\text { agreed timescales, and staff are protected } \\
\text { from unintentional exposure. }\end{array}$ & $\begin{array}{l}\text { Quality and timeous services from Laboratory and X-rays. Staff and } \\
\text { patients are protected from unnecessary exposure. (PPE's). Films and } \\
\text { reagents are stored and disposed of according to guidelines. }\end{array}$ & $\begin{array}{l}\text { Records } \\
\text { Critical stock levels lists } \\
\text { Records } \\
\text { PTC with terms of reference. }\end{array}$ & & \\
\hline $\begin{array}{l}3.3 \text { Therapeutic } \\
\text { Services. }\end{array}$ & $\begin{array}{l}\text { Blood for transfusion is available within } \\
\text { an acceptable time. Rehabilitation and } \\
\text { social support services are available } \\
\text { where needed by the respective/relevant, } \\
\text { professional staff. }\end{array}$ & $\begin{array}{l}\text { Blood and blood products are available to support care. Rehabilitation } \\
\text { and social support services are available Patient treatment is holistic and } \\
\text { includes comprehensive multi-disciplinary therapeutic programmes. } \\
\text { Patients requiring social support are assessed according to protocols. }\end{array}$ & $\begin{array}{l}\text { Recommendations on } \\
\text { Antibiotic usage-Anti } \\
\text { microbial stewardship } \\
\text { program. }\end{array}$ & & \\
\hline $\begin{array}{l}\text { 3.4 Health } \\
\text { Technology } \\
\text { Services. }\end{array}$ & $\begin{array}{l}\text { Medical equipment for safe and effective } \\
\text { patient care is available and functional. } \\
\text { Staff are trained in the correct use of } \\
\text { medical equipment. }\end{array}$ & $\begin{array}{l}\text { Medical equipment meets minimum requirements for the appropriate } \\
\text { level of care. Staff are trained in the correct use of medical equipment. } \\
\text { Medical devices are maintained to ensure safety and functionality. } \\
\text { Critical devices are regularly serviced. }\end{array}$ & & & \\
\hline $\begin{array}{l}\text { 3.5Sterilization } \\
\text { Services. }\end{array}$ & $\begin{array}{l}\text { Decontamination and sterilisation } \\
\text { services are available and effective. }\end{array}$ & $\begin{array}{l}\text { System is in place for decontamination of surgical instruments. Suitably } \\
\text { qualified staff manages the sterilisation department. Clear lines of } \\
\text { accountability exist for the decontamination cycle. Sterilisation } \\
\text { equipment meets legislative requirements. Biological and processing } \\
\text { tests. All sterilisation failures are monitored. }\end{array}$ & & & \\
\hline $\begin{array}{l}\text { 3.6 Mortuary } \\
\text { Services. }\end{array}$ & $\begin{array}{l}\text { There is a process for the care and } \\
\text { removal of the dead. }\end{array}$ & $\begin{array}{l}\text { Policies and procedures guide all aspects of storage, removal and } \\
\text { transportation of bodies. }\end{array}$ & & & \\
\hline $\begin{array}{l}\text { 3.7 Efficiency } \\
\text { management. }\end{array}$ & $\begin{array}{l}\text { Clinical efficient and cost effective safe, } \\
\text { quality patient care is rendered. }\end{array}$ & $\begin{array}{l}\text { Effective and efficient case management systems are in place. } \\
\text { Integration of cost effective care. }\end{array}$ & & & \\
\hline
\end{tabular}




\section{Conclusion}

Much effort on the part of National Department of Health and the Office of Health Standards Compliance in South Africa has been placed on the NCS. The results of the study revealed that the NCS and the Batho Pele principles are not fully implemented or evaluated in the selected private hospitals in eThekwini district. These findings were significant and denoted the need for a standardised clinical audit tool for private hospitals in eThekwini district.The results of the study identified the strengths and weakness of the selected hospitals in regards to its clinical governance. The recommendations and proposed audit tool are intended to create a positive organisational culture and workforce that is committed to strengthening the national quality framework within eThekwini district.

\section{Recommendations}

Recommendations that the researchers propose in this section are based on actions on three fronts, namely, management responsibility; education and training and stakeholder responsibility. It is important that the three levels of hierarchy co-operate to put systems and processes into place to implement the National Quality Framework of the NCS and Batho Pele principles within eThekwini private hospitals. Communication between the three levels and with relevant stakeholders that is the National Department of Health in eThekwini district is important. The researcher further recommends that future researchers on the topic engage in a broader study involving other private hospitals and groups in eThekwini district. Performing research of this nature will develop baseline findings of what eThekwini private hospitals have to offer and this may be the start of setting up an integrated quality and infection control forum and other networks in eThekwini district. This may lead to creating a centralised data base for hospitals to benchmark their quality scorecards, learn new ideas and implement best practices to render safe quality care. Further research on the evaluation of the audit tool is also highly recommended. The proposed audit tool could enhance the successful implementation of the NCS and Batho Pele principles in private hospitals in eThekwini hospital.

\section{Limitations of the study}

This is a single site study within a specific group of hospitals in a specific geographical location (eThekwini), therefore findings may not be able to be generalized across other private hospitals due to sampling bias.
We certify that the article is original work, has not previously been published, and is not currently under consideration by another journal.

\section{Conflict of interest}

The authors declare that they have no conflict of interests.

\section{Acknowledgements}

Authors would like to acknowledge the Durban University of Technology for funding this research study.

\section{References}

1. Whittaker S, Shaw S, Spieker N, Linegar A. Quality standards for healthcare establishments in South Africa 2011; 1-60.

2. Republic of South Africa. Department of Health. Towards Quality Care for Patient's National Core Standards for Health Establishments in South Africa, Government Printer, Pretoria 2011; 1-52.

3. WHO. How can hospital performance be measured and monitored? WHO, Geneva; 2010.

4. Matsebula T, Willie M. Private hospitals. Health care delivery. South African Health Review 2007; 159-174.

5. Boshoff C, Gray B. The relationships between service quality, customer satisfaction and buying intentions in the private hospital industry. South African Journal of Business Management 2004; 35: (4) 27-37.

6. Republic of South Africa. Department of Health .Norms and Standards Regulations Applicable to Different Categories of Health Establishments, National Health Act, 2003, Government Printer, Pretoria 2017;148.

7. Republic of South Africa. Department of Public Service and Administration. White Paper on Transforming Public Service Delivery (Batho Pele White Paper) (No. 1459 of 1997), Government Printer, Pretoria 1997; $1-25$.

8. Republic of South Africa. Department of Health .Control of Private Hospitals, Regulation 158. Government Printer, Pretoria 1996; 1-55.

9. Republic of South Africa. Department of Health. The National Health Care Facilities Baseline Audit National Summary Report, Government Printer, Pretoria 2012; 1-67.

10. Kabane S. The evaluation of the effectiveness of a hospital clinical adverse event prevention program. Ph.D. thesis, University of Pretoria 2013; 1-32.

11. Creswell J W. Research design: qualitative, quantitative, and mixed methods approach. $4^{\text {th }}$ edition, Los Angeles, Sage 2014; 33-297. 
12. Blewett L A, Parente S T, Peterson E, Finch M D. The role of the private sector in monitoring health care quality and patient safety: The Joint Commission Journal on Quality and Safety 2003; 29: (8) 425-433.

13. Ensor T, Palmer P. The oversight and regulation of non-state health care providers: a rapid review in selected middle and high-income countries. Oxford Policy Management (OPM), Oxford, UK 2009; 5-7.

14. Gaw A, O’Neill F H. Ethics in research: Practice and respect. Nursing Times 2014; 110: (20) 12-13.
15. Joint Commission International (JCI). Standards for hospitals. $4^{\text {th }}$ edition, Oakbrook Terrace, ILL: The Joint Commission 2011; 36-191.

16. WHO. All Party Parliamentary Group on Global Health: Triple Impact of Nursing. APPG on Global Health. WHO, Geneva; 2016.

17. Loh J. Inquiry into issues of trustworthiness and quality in narrative studies. A perspective. The Qualitative Report 2013; 18(33): 1-15. 